\title{
Attitudes and Perceptions Towards Coronavirus Disease 2019 (COVID-19) Vaccine Acceptance Among Recovered African American Patients
}

$\mathrm{J}$ Gen Intern Med 36(7):2186-8

DOI: $10.1007 / \mathrm{s} 11606-021-06787-5$

(c) Society of General Internal Medicine 2021

\section{BACKGROUND}

Moderna and Pfizer-BioNTech COVID-19 vaccines were approved in December 2020 and vaccinations have since commenced $^{1}$. Both vaccines reported efficacy rates $>90 \%$ during clinical trials ${ }^{1}$. Adequate vaccine uptake is necessary to effectively combat the COVID-19 pandemic.

Though African Americans are disproportionately affected by COVID-19 compared to other racial groups in the USA, a survey of US adults showed that African Americans had the lowest COVID-19 vaccine acceptance rate ${ }^{2}$. Historically, African American adults are less likely than non-Hispanic whites to receive recommended vaccines partly due to a perceived higher risk of side effects and distrust in the healthcare system $^{3}$.

It is unclear how long natural immunity from a previous COVID-19 infection lasts, with some studies reporting up to 6 months ${ }^{4}$. Therefore, the center for disease control and prevention (CDC) recently recommended vaccination regardless of previous infection ${ }^{5}$. We evaluated the acceptability of COVID-19 vaccination among African American patients after recovery from COVID-19 infection. This study was conducted during the development stages of COVID-19 vaccines and there was no definitive $\mathrm{CDC}$ on vaccination in recovered patients at the time.

\section{METHODS}

African American patients hospitalized with COVID-19 infection at the Grady Memorial Hospital in Atlanta, GA, between April 1, 2020, and May 30, 2020, were asked to participate in the study after recovery and discharge from the hospital. Participants completed a survey in July 2020, on the likelihood to accept a "proven safe and effective" vaccine and factors impacting their decisions. The survey questions on reasons for potentially declining vaccination were developed

Received December 14, 2020

Accepted March 31, 2021

Published online April 26, 2021 based on previous research on influenza vaccine acceptance in the $\mathrm{USA}^{3}$. Respondents were given information on COVID19 vaccines from the CDC and Advisory Committee on Immunization Practices working group updates in June, $2020^{6}$.

Patients' demographic and comorbidity data were obtained from the electronic health record system. The study was approved by the Morehouse School of Medicine institutional review board and verbal informed consent was obtained from the participants.

\section{FINDINGS}

Out of 132 eligible patients, 119 completed the survey. Table 1 summarizes the characteristics of surveyed patients. The median age was 64 years (IQR, 54.5-73.5 years) and 58\% were men. The most prevalent comorbidity was hypertension $(68 \%)$ followed by diabetes mellitus (33\%) and heart failure (20\%). Overall, $30 \%$ responded they would accept a vaccine COVID19 vaccine, $54 \%$ responded they would not, while $16 \%$ were undecided. On chi-squared analysis, male sex and uninsured status were associated with a higher chance of accepting vaccination while patients with congestive heart failure, coronary artery disease, diabetes mellitus, and hypertension were more likely to decline.

In Figure 1, the major reasons provided by participants for potentially declining COVID-19 vaccination were combination of distrust in the vaccine efficacy irrespective of what the research shows and distrust of the pharmaceutical companies that produce vaccines $(78 \%)$, fear of vaccination side effects (65\%), and perceived immunity against COVID-19 re-infection $(29 \%)$.

\section{DISCUSSION}

Our study shows that only 3 out of 10 African American patients who recovered from COVID-19 infection will accept a "safe and effective" COVID-19 vaccine. Interestingly, this uptake rate is lower than previously reported among noninfected African Americans (40\%) ${ }^{2}$. Though the perception of immunity against COVID-19 re-infection by almost onethird of the respondents may have contributed to the low acceptability rate, most of the patients intend to decline vaccination due to lack of trust in the vaccine effectiveness and 
Table 1 Characteristics of Patients and COVID-19 Vaccine Acceptability

\begin{tabular}{|c|c|c|c|c|c|c|}
\hline \multirow[t]{2}{*}{ Variables } & \multirow[t]{2}{*}{ Total $N(\%)$} & \multicolumn{3}{|c|}{ Intention to receive COVID-19 vaccine } & \multicolumn{2}{|l|}{$P$ value } \\
\hline & & No $N(\%)$ & Undecided $N(\%)$ & Yes $N(\%)$ & Yes vs. no & Yes vs. undecided \\
\hline Total, $N(\%)$ & 119 & $64(54)$ & $19(16)$ & $36(30)$ & \multirow{4}{*}{0.04} & \multirow{4}{*}{0.25} \\
\hline \multicolumn{5}{|l|}{ Gender } & & \\
\hline Female & $50(42)$ & $31(62)$ & $8(16)$ & $11(22)$ & & \\
\hline Male & $69(57.9)$ & $33(47.8)$ & $11(15.9)$ & $25(36.2)$ & & \\
\hline \multicolumn{5}{|l|}{ Age (median 64y, IQR [54.5-73.5]) } & \multirow[t]{5}{*}{0.31} & \multirow[t]{5}{*}{0.40} \\
\hline $18-34 y$ & $7(5.8)$ & $5(71.4)$ & $0(0)$ & $2(28.5)$ & & \\
\hline $35-49 y$ & $16(13.5)$ & $10(62.5)$ & $3(18.7)$ & $3(18.7)$ & & \\
\hline $50-74 y$ & $69(57.9)$ & $34(49.2)$ & $13(18.8)$ & $22(31.8)$ & & \\
\hline$>75 y$ & $27(22.6)$ & $15(55.6)$ & $3(11.1)$ & $9(33.3)$ & & \\
\hline \multicolumn{5}{|l|}{ Health insurance } & \multirow[t]{4}{*}{$<0.01$} & \multirow[t]{4}{*}{0.03} \\
\hline Medicare or Medicaid & $53(44.5)$ & $37(69.8)$ & $6(11.3)$ & $10(18.8)$ & & \\
\hline Private insurance & $46(38.6)$ & $21(45.65)$ & $11(23.9)$ & $14(30.4)$ & & \\
\hline Uninsured & $20(16.8)$ & $6(30)$ & $2(10)$ & $12(60)$ & & \\
\hline \multicolumn{7}{|l|}{ Comorbidities } \\
\hline Asthma & $15(12.6)$ & $9(60)$ & $2(13.3)$ & $4(26.7)$ & 0.07 & 0.12 \\
\hline Coronary artery disease & $25(21.1)$ & $16(64)$ & $3(12)$ & $6(24)$ & 0.02 & 0.35 \\
\hline Cancer & $9(7.6)$ & $5(55.6)$ & $2(22.2)$ & $2(22.2)$ & 0.18 & 0.26 \\
\hline Congestive heart failure & $24(20.2)$ & $16(66.7)$ & $3(12.5)$ & $5(20.8)$ & $<0.01$ & 0.79 \\
\hline Chronic kidney disease stage 3 and above & $14(11.7)$ & $9(64.2)$ & $2(14.3)$ & $3(21.4)$ & 0.03 & 0.47 \\
\hline Chronic obstructive pulmonary disease & $17(14.9)$ & $10(58.8)$ & $2(11.7)$ & $5(29.4)$ & 0.05 & 0.27 \\
\hline Cerebrovascular accident & $11(9.2)$ & $7(63.6)$ & $0(0)$ & $4(36.6)$ & 0.11 & 0.36 \\
\hline Diabetes mellitus & $39(32.7)$ & $24(61.5)$ & $5(12.8)$ & $10(25.6)$ & $<0.01$ & 0.04 \\
\hline HIV/AIDS & $5(4.2)$ & $0(0)$ & $0(0)$ & $5(100)$ & - & - \\
\hline Hypertension & $68(57.4)$ & $36(52.9)$ & $10(14.7)$ & $22(32.5)$ & $<0.01$ & $<0.01$ \\
\hline Obstructive sleep apnea & $8(6.7)$ & $4(50)$ & $2(25)$ & $2(25)$ & 0.08 & 0.49 \\
\hline \multicolumn{5}{|l|}{ No of comorbidities } & \multirow{3}{*}{0.30} & \multirow[t]{3}{*}{0.02} \\
\hline No comorbidities & $22(18.4)$ & $13(59.1)$ & $2(9.1)$ & $7(31.8)$ & & \\
\hline$\geq 1$ comorbidity & $97(81.5)$ & $51(52.6)$ & $17(17.5)$ & $29(29.9)$ & & \\
\hline \multicolumn{5}{|l|}{ Body mass index (BMI) } & \multirow[t]{4}{*}{0.13} & \multirow[t]{4}{*}{0.41} \\
\hline$<30 \mathrm{~kg} / \mathrm{m}^{2}$ & $54(45.4)$ & $25(46.3)$ & $9(16.7)$ & $20(37.4)$ & & \\
\hline$\geq 30$ to $<35 \mathrm{~kg} / \mathrm{m}^{2}$ & $8(6.7)$ & $4(50)$ & $1(12.5)$ & $3(37.5)$ & & \\
\hline$\geq 35 \mathrm{~kg} / \mathrm{m}^{2}$ & $57(47.9)$ & $35(61.4)$ & $9(15.8)$ & $13(22.8)$ & & \\
\hline \multicolumn{5}{|l|}{ Current tobacco use } & \multirow[t]{3}{*}{0.25} & \multirow[t]{3}{*}{0.57} \\
\hline No & $78(65.5)$ & $41(52.5)$ & $13(16.7)$ & $24(30.7)$ & & \\
\hline Yes & $41(34.5)$ & $23(56.1)$ & $6(14.6)$ & $12(29.2)$ & & \\
\hline
\end{tabular}

$\chi^{2}$ tests were used to estimate associations between participant characteristics and intention to receive COVID-19 vaccine. 2 separate $\chi^{2}$ tests and associated P values were calculated to better distinguish characteristics associated with responses of "yes" versus "no" and characteristics associated with responses of "yes" versus "undecided"

pharmaceutical industries developing vaccines. These findings likely stem from skepticism towards healthcare research within the African American community justified by previous unethical mistreatment, experimentation, and exploitation ${ }^{3}$.

\section{Reasons for declining COVID-19 vaccine}

I do not trust that COVID-19 vaccine will be effective

Fear of side effects from COVID-19 vaccine

I do not trust the pharmaceutical companies that make vaccines Distrust of both vaccine effectiveness and pharmaceutical industries

Previous bad experience with vaccines especially influenza

COVID-19 vaccine could make my pre-existing medical condition worse

I am immuned against COVID-19 reinfection

I am generally against vaccines

COVID-19 is not a severe disease

Advised against vaccination by medical provider

I do not have health insurance
The drive for COVID-19 vaccination should not stop at developing a safe and effective vaccine. African Americans will likely trust and accept vaccines if recommended by their healthcare providers, especially if they share similar race or
Percentage $(95 \% \mathrm{Cl})$

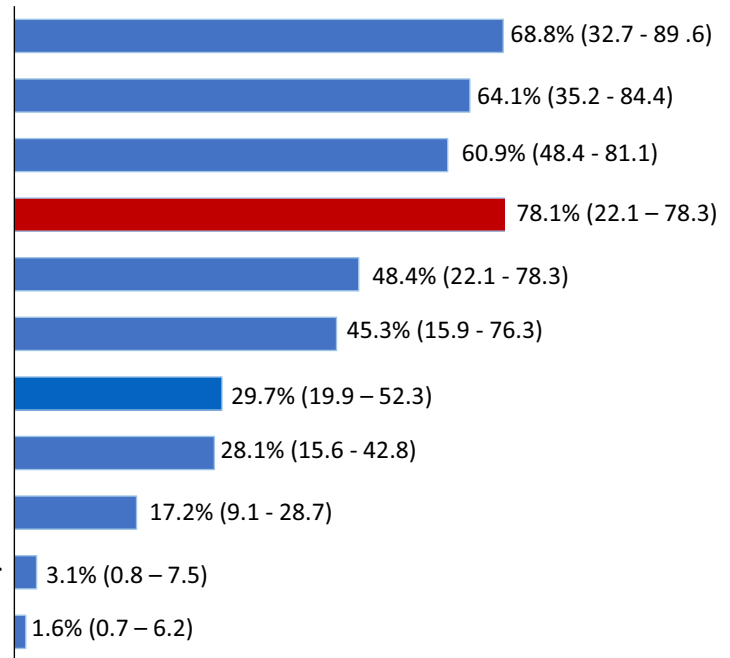

Figure 1 Reasons participants provided for responding "no" to COVID-19 vaccination. Respondents provided reasons in more than one category. 
ethnicity and live in the same community ${ }^{3}$. Medical providers and community-based advocacy groups should work together to rebuild trust and dispel the misconceptions around COVID19 vaccines.

This is a single-center cross-sectional study limited by its small sample size. We also recognize that the study was conducted early on during the pandemic and perspectives may have changed over time with more available information on COVID-19 vaccines. Additionally, our study population was restricted to African Americans which limits the ability to compare vaccine hesitancy with other ethnicities.

Titilope Olanipekun, $M D, M P H^{1,2}$

Temidayo Abe, $M D^{2}$

Valery Effoe, $M D, M S^{2,3}$

Suaka Kagbo-Kue, $\mathrm{MD}^{2,4}$

Iloabueke Chineke, $\mathrm{MD}^{2,5}$

Chinedu Ivonye, $M D^{2}$

Nicolas Bakinde, $\mathrm{MD}, \mathrm{PhD}^{2}$

${ }^{1}$ Department of Hospital Medicine, Covenant Health System,

Knoxville, TN, USA

${ }^{2}$ Department of Internal Medicine, Morehouse School of Medicine,

Atlanta, GA, USA

${ }^{3}$ Division of Cardiology, Morehouse School of Medicine,

Atlanta, GA, USA

${ }^{4}$ Department of Gastroenterology and Hepatology, Mayo Clinic,

Scottsdale, AZ, USA

${ }^{5}$ Department of Hematology and Oncology, University of Arizona,

Phoenix, AZ, USA
Corresponding Author: Titilope Olanipekun, MD, MPH; Department of Hospital Medicine, Covenant Health System, Knoxville, TN, USA (e-mail: titilope_olanipekun@teamhealth.com).

Author Contribution All authors contributed to the writing of the manuscript.

\section{Declarations:}

Conflict of Interest: The authors declare that they do not have a conflict of interest.

\section{REFERENCES}

1. Ledford $\mathbf{H}$. Moderna COVID vaccine becomes second to get US authorization. Nature. Published online 2020. doi:https://doi.org/10.1038/ d41586-020-03593-7

2. Malik AA, McFadden SAM, Elharake J, Omer SB. Determinants of COVID-19 vaccine acceptance in the US. EClinicalMedicine. 2020;26. doi:https://doi.org/10.1016/j.eclinm.2020.100495

3. Quinn SC. African American adults and seasonal influenza vaccination: Changing our approach can move the needle. Hum Vaccines Immunother. 2018;14(3):719-723. doi:https://doi.org/10.1080/21645515.2017. 1376152

4. Figueiredo-Campos P, Blankenhaus B, Mota C, et al. Seroprevalence of anti-SARS-CoV-2 antibodies in COVID-19 patients and healthy volunteers up to six months post disease onset. Eur $J$ Immunol. Published online 2020. https://doi.org/10.1002/eji.202048970

5. Centers for Disease Control and Prevention. Interim Clinical Considerations for Use of mRNA COVID-19 Vaccines Currently Authorized in the United States. Updated January 6, 2021. Available at https://www.cdc. gov/vaccines/covid-19/info-by-product/clinical-considerations.html. Accessed on January 31, 2021

6. Centers for Disease Control and Prevention. The Advisory Committee on Immunization and Practices' Work Group Presentation and Updates on COVID-19 Vaccines. June 24, 2020. Available at https://www.cdc.gov/ vaccines/acip/meetings/slides-2020-06.html. Accessed on July 7, 2020.

Publisher's Note: Springer Nature remains neutral with regard to jurisdictional claims in published maps and institutional affiliations. 